\title{
Review of water energy food nexus in Africa: Morocco and South Africa as case studies
}

\author{
Lahcen El Youssfi ${ }^{1}{ }^{*}$, Wesley Doorsamy*2, ${ }^{2}$ dilAghzar ${ }^{1}$, Sidi Imad Cherkaoui ${ }^{1}$, Ihssan Elouadi $^{3}$, Alex Godoy Faundez ${ }^{4}$, and \\ Diego Rivera Salazar ${ }^{4,5}$ \\ ${ }^{1}$ Research team of environment and natural resources management, B2DRN Laboratory, Khenifra Higher School of Technology, Sultan \\ Moulay Slimane University, Morocco \\ ${ }^{2}$ Institute for Intelligent Systems, University of Johannesburg, South Africa \\ ${ }^{3}$ École Nationale Supérieure des mines de Rabat, ENSMR, Morocco \\ ${ }^{4}$ CISGER, Facultad de Ingenieria, Universidad del Desarrolo, Chile \\ ${ }^{5}$ CRHIAM, University of Conception, Chile \\ ${ }^{*}$ Equally contributed to this work.
}

\begin{abstract}
The population of the African continent is significantly increasing which has given rise to societal, economic and environmental changes. This will generate an increase in demand for food, water and energy. Thus, strategies for sustainable management of natural resources need to be adopted urgently in order to match the future needs and to ensure sustainable development on the continent. The Water Energy Food (WEF) nexus is one the avenues for studying the current and future interactions and interdependencies of the WEF sectors under different scenarios and challenges in the effort towards establishing sustainable use of natural resources. Policies around the nexus approach are few or absent at the continental and countrylevels. This paper is a first review on the adoption of the Nexus in two model African countries, Morocco and South Africa. The review compares the water, energy and food sectors and the related national policies, plans and frameworks. The data related to the WEF Nexus revealed key difficulties of availability in both countries. A comparative analysis of the situation in both countries demonstrated differences in policies relating to the WEF Nexus across the sectors: water, energy, and agriculture. Additionally, the paper explores the relevance of technology-assisted frameworks for the WEF nexus and also analyzed risks to agriculture and food security in the context of the reviewed countries.
\end{abstract}

\section{Introduction}

Africa's population is rapidly increasing and along with this is an increasing demand for food, water and energy. This places a tremendous strain on natural resources: soil, water and natural energy sources, especially for food production. The situation is further compounded by extreme societal, economic and environmental changes. Thus, African countries need to account for these changes in their long-term sustainable development strategies. The nexus of water, energy and food is seemingly becoming more critical for developing new adaptation and mitigation strategies to reduce the negative consequences of over-exploitation of natural resources and thus provide a more sustainable and resilient food production systems.

The use of precision technology in food production systems is one of the promising solutions for limiting and reducing over-exploitation of natural resources and pollution of the production ecosystem. In fact, innovative research and development programs and initiatives that focus on the role of technology in large scales and agricultural technology in small scales are required in addressing nexus challenges across Africa. The ability of the African countries to develop and to use low-cost, accessible and affordable agricultural technologies is thus a critical point of interest. This coincides with resolving the challenge of promoting small scale farmers so as to provide them with access to technology that is currently

acCorresponding author:1.elyoussfilahcen@usms.ma 
not available/accessible to them. This could potentially support economic growth through enhancing small-scale farming, as well as promoting sustainability in the vast arable lands of Africa.

According to the OECD, a 55\% increase in water demand by 2050 is predicted, and the FAO projects that food production will need to increase by $70 \%$ by 2050 , and the IEA (US Energy Information Administration) expects energy demand will increase by $40 \%$ in 2030 [1].The future of the nexus will undoubtedly become more complex in all directions. Through considering agriculture as the most important economic activity in Africa as it provides food, not only for its population, but also for other populations on other continents, and the water and energy consumption thereof, optimizing water and energy in agriculture and food production is found to be a necessary focus.

Taking the aforementioned into consideration, the Nexus is studied and adopted because it's an evidentiary-based approach with which to develop scenarios, as well as to design and appraise potential options, and a means for supporting multi-stakeholder dialogue. This paper is aimed at drawing an overview on the Water Energy Food Nexus and its reflections on the sustainability of the concerned resources in agriculture and on food security with particular focus on Morocco and South Africa. The relevant sectors were reviewed in the context of these countries, primarily focusing on their interactions. The potential impact of the development and the use of technology-assisted frameworks to support the nexus approach is briefly explored. The detailed review and comparative analysis of the studied countries were then presented.

\section{Overview on Water Energy Food Nexus}

\subsection{The nexus}

The nexus corresponds to the central link or the important connection associating different elements and parts of a system. The Water Energy Food Nexus (WEF Nexus) corresponds to the connections and the interdependencies of water, energy and food as a system or as three unique systems [2].The study of the WEF Nexus aimed to define the different components and aspects of the interdependencies of these systems. The interdependencies are multidimensional and very complex are difficult to study. In fact, the nexus is treated from different angles and aspects in order to desegregate the interdependencies. On the other hand, the interactions of the Nexus with other systems are also considered while dealing with Nexus challenges.

Water is utilized in agriculture for irrigation and food processing. Water is also essential for energy generation, whether directly in the case of hydropower or indirectly in coal mining. Energy is utilized in the pumping and distribution of water and for the mechanization of various agricultural activities. The nexus approach to resource sector management seeks to understand the linkages, dependencies, and trade-offs associated with the core elements within the nexus under assessment [3].

Many connections can be evaluated in interaction with the WEF Nexus; for instance, climate change, food security, water management, energy security and others.

\subsection{Water Energy Food nexus and resource security}

The WEF Nexus is important because of the importance of food, energy and water as resources and systems. Those resources are not only pillars of the economy of a nation but critically important for its security and not only the natural resources security. The increase of population increases the pressure on the available resources of food, water and energy; and countries exports and/or imports one or two or all the resources in order to maintain equilibrium and to satisfy domestic demand on those resources. In this way countries have to face the challenge of ensuring resource security. In addition, the sustainability of resources is associated key challenge for the different countries. This process is also influenced by external factors such as political, geopolitical, international relations and others. In this sense, food, water and energy security form the basis of a self-sufficient economy of a country [4]. In fact, resources security can be evaluated separately or maybe overviewed based on an integrated evaluation of different resources via the nexus and in interaction with others.

\subsection{Water Energy Food nexus and food security}

Food security has several indicators or pillars: availability, accessibility and utilization. These pillars are related and influenced by many factors. Food availability relates to the supply of food through production, processing distribution, and 
exchange. Food production is determined by a variety of factors including land ownership and use; crop, water and soil management; crop management. Food accessibility is related to affordability, purchasing power, transport and other factors. Utilization of food is related to food quality and safety, health and sanitation conditions, clean water and other factors. In fact, food security is influenced by complex systems and various factors; however, food production related factors can be the most important one; because it's the most important source of food at the local food then comes trade and imported/exported food. An efficient food production system requires a robust agricultural system and strong economic growth. But, a robust agriculture includes energy and industrial crops, not just food and it's also water consuming especially in irrigated areas. Agriculture is responsible for an important freshwater overuse. According to UNESCO, irrigated agriculture is actually responsible for about more than $70 \%$ of freshwater abstractions by humans.

Energy is required for the entire food system including food production, harvesting, transport, processing, packaging, and marketing. This has received limited attention in the water-energy-food nexus discourse so far, but is an important factor that needs to be considered [1]. And it's also important to mention that when there is an increase in agricultural productivity, the agricultural sector is supposedto become a more significant energy consumer. Going forward in this process, it is clear that energy will be a fundamental input to ensure universal food security [5].

Food production further affects the water and energy sectors through degradation of land, changes in overflow, disturbance of groundwater release, water quality, accessibility of water and land for different purposes [6]. In this way, an important pillar of food security is perturbed which is the food production ecosystem.

There is uncertainty in the food and agricultural sector with regards to policies and plans that are directly linked to the WEF nexus. As population increases a substantial increase in agricultural productivity is required. However, action plans do not consider the fact that the expansion requires more land, water and energy resources. Consequently, there is a need for changing and revisiting existing water and agricultural policies in order to prevent the impacts of increasing agricultural productivity on water and energy resources [3, 4].

A healthy WEF nexus requires the development of a sustainable agricultural policy through efficient land use and good planning, good linking between food production systems to ecosystems, innovative redesigning of waste management policy as well as new formulation of a proficient water quality strategy [3]. Several initiatives and policies were implemented in different part of the continent and worldwide which are environmentally friendly but there is still a need for more ones and more coordinated and impactful ones.

\subsection{Water Energy Food nexus and climate}

The exposure of the nexus components to climate is gaining more and more importance, especially under the risk of climate change. This aspect concerns the evaluation of the interaction between characteristics of the climate system, inter-annual rainfall variability for example, and the dependence of a country on climate-sensitive economic activities such as agriculture and sectors such as drinking water and energy production from hydroelectric sources [2].

Climate plays an important role in determining medium-term water availability, potential agricultural production and some components of energy production and demand. Climate variability drives fluctuations in water-energy-food elements with secondary effects across the whole nexus. Exposure to climate variability and climate change are high across nexus sectors that include substantial areas of economic activity in southern Africa and there is strong evidence of the effects of individual climate events [2].

\subsection{Technology-assisted Frameworks for Water Energy Food nexus}

The role of innovative technologies towards achieving sustainability is well recognized. Effective management of water and energy resources - particularly with competing large-scale usage models - implores technological intervention. For example, energy and water sectors are amongst the most significant consumers of others as a resource, globally. While there is certainly a need for basic research for transforming fundamental approaches in this regard, applied research and technological developments can assist with disrupting current practices relating to these resources - i.e. generation, transport, consumption etc. [7].

Recently, there have been tremendous technological advancements - particularly in the area of agriculture. From the Internet of Things (IoT) to enhanced Earth observation, recent technological advancements provide new avenues of better understanding, monitoring and regulating the nexus interactions. The complexity of the WEF nexus provides a challenge, in 
that, the interactions themselves are difficult to model, monitor and regulate. Thus, technology is fast becoming a critical enabler for development and implementation of WEF nexus frameworks, especially when scalability, flexibility and robustness are sought after features.

Modelling WEF interactions is highly complex and context specific [8], and there has been much work involving computer-based modelling of various issues within the sphere of the WEF nexus. There are several different modelling approaches put forward that vary according to modeling priorities/goals, scale and interdependencies of interest, as summarized in [9]. For example, [10] proposes a computational decision framework for modelling and analysing WEF nexus particularly in risk adverse environments. Another recent example of computational modelling in this area is presented by [11] which deal specifically with optimizing land use - in a WEF nexus framework - for agriculture application.

Technological advancements are also aiding in overcoming some of the key challenges towards implementation and utilization of the aforementioned frameworks. [12] discusses some of these key challenges: limited observability within and across WEF systems; observation data management and access (protocols) - when observation data are available - are generally inadequate. Although there is inadequate sharing of regional and global observation data is inadequate, the widespread availability of pervasive computing and IoT with the cost-effective wireless sensor technologies provides the opportunity for generating useful observation data to furnish and operationalize these WEF frameworks. An example of this is remote sensing technology - inter alia satellite-based remote sensing, aerial (manned or unmanned) vehicle, ground vehicles, ground-based sensor networks, advanced metering - which enables cheaper, robust and high-spatiotemporal resolution data collection [13].

\section{Reflections on food security in Morocco and South Africa}

\subsection{South Africa}

\subsubsection{Agriculture in SA: Overview}

South Africa's agriculture sector contributes by about 2.5\% to its Gross Domestic Product (GDP), and has seen an average decline since $1993[14,15,16]$. Although the agriculture sector itself makes a relatively small contribution to the country's GDP, the agri-food system accounts for a substantially larger GDP contribution at approximately 14\% [14], which has increased over the years due to supermarket expansions and further separation between the food consumer and producer. Generally, the total number of commercial farms in South Africa has decreased over the years, but farms have increased in average size and their usage of technology. This has led to a steady decline in manual labor resulting in jobs losses in both casual and permanent type work categories. The agriculture economy in South Africa is market-oriented with a highly diversified production portfolio including all major grains - excluding rice - subtropical fruits, oilseeds, sugar, citrus, wine, several vegetables, cattle, diary, hogs, sheep, poultry and eggs [17].

In addition to several major challenges that South African agriculture faces, the government recognizes two of the foremost threats to food security as climate change and sustainable resource management [14]. This is further compounded by growing population and declining farm yields. And the declining yields are owing to water and energy constraints as well as unsustainable land-use practices.

\subsubsection{Risks to agricultural food production}

\section{- Water quality and availability}



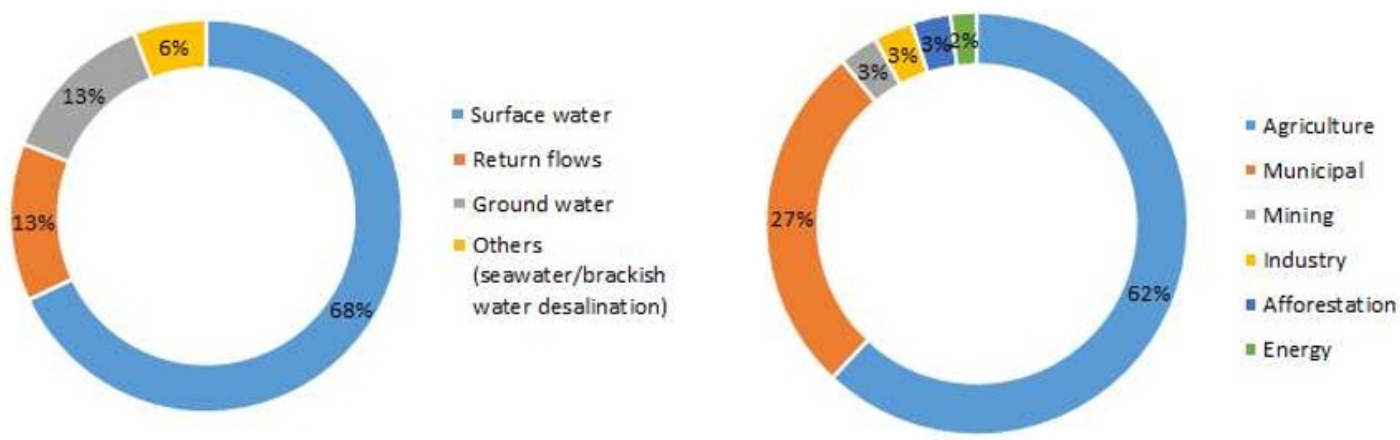

Fig.1.Water sources and usage by sector in South Africa [18]

South Africa has a semi-arid climate and is amongst the driest countries in the world ranking $30^{\text {th }}$ in this regard [19]. This means that the water scarcity problem due to increasing demand, and drought resulting from climate change exacerbate the general water resource challenge in the country. In recent years, due to these constraints, the agricultural yields particularly major grains - have been inexorably at the mercy of drought. Agriculture is by far the majority user of water in South Africa accounting for approximately $62 \%$ of the total water usage. The figure below shows the fluctuating agricultural yields (as contribution in ZAR millions to SA GDP) which were directly linked to droughts in the 2015 season, rainfall in the 2016/2017 and drought once again in the 2017/2018 season [20]. This drought period continued into 2019, and was found to be the worst in the past 100 years in the country's history [16].

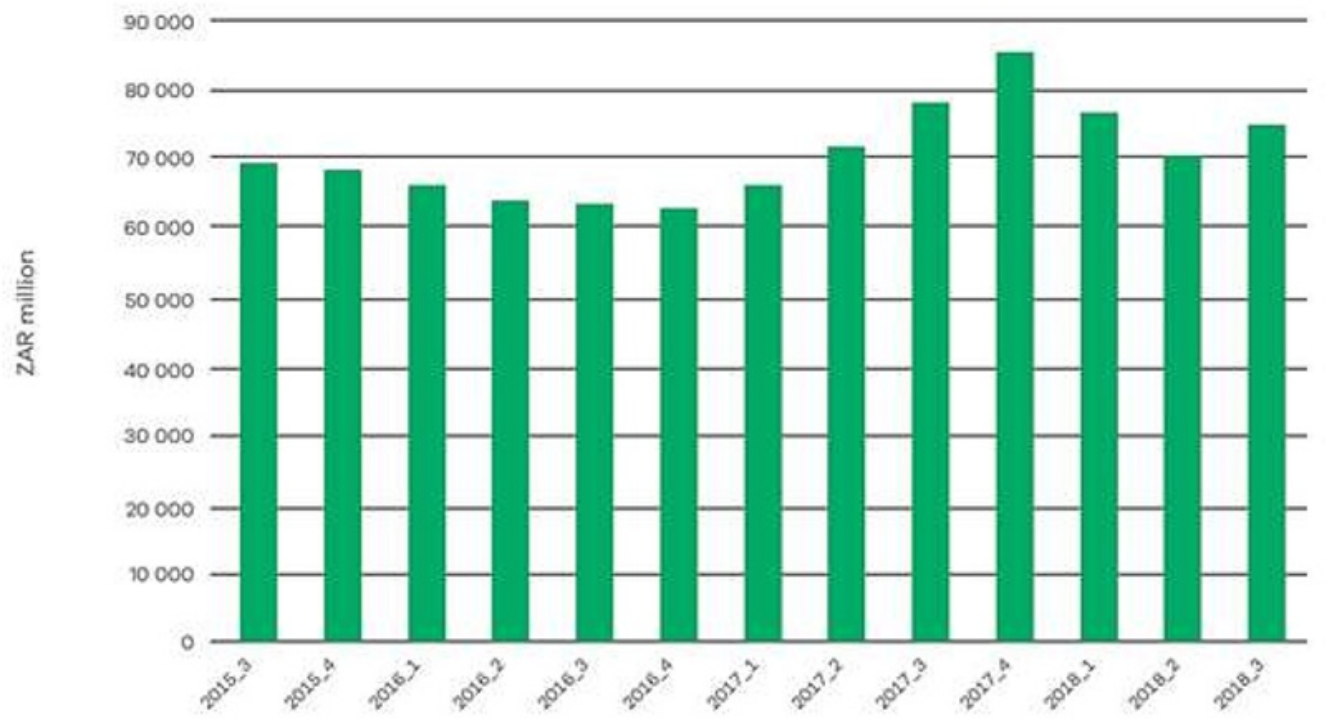

Fig.2. South African GDP from agriculture per quarter[20]

\section{- Electricity availability, reliability and cost}

The energy infrastructure of any country forms a crucial component of the country's economic lifeblood. In South Africa, the vast majority of the nation's energy is provided through one state-owned utility. In terms of energy sources, coal is the main source of electricity generation accounting for around $83 \%$ of the total mix - with nuclear, gas and pumped storage forming the other significant components. Since the dawn of democracy in the country, there has been a steep rise in demand, particularly with the noted increase in industrialization and massive electrification programmes for providing access to citizens via the National Development Plan.

Together with the steady increase in the country's demand, the lag in establishment of new generation capacity coupled with ageing generation fleets have resulted in an energy crisis [21]. This energy crisis has culminated in rolling blackouts 
and a destabilized grid which has occurred intensely over different periods beginning in 2007 and is still ongoing. This has had major impacts on all sectors of the economy. According to the World Bank, the Co2 emissions reached a value of 9 million tons per capita which comes mainly from consumption of energy, electricity production and industry.

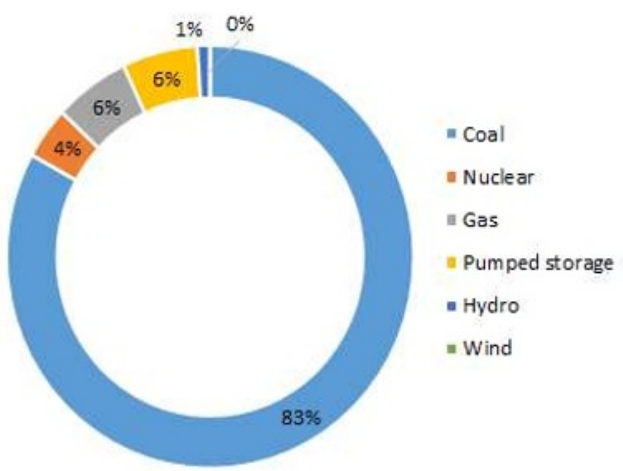

Fig.3. Energy generation mix in South Africa [22]

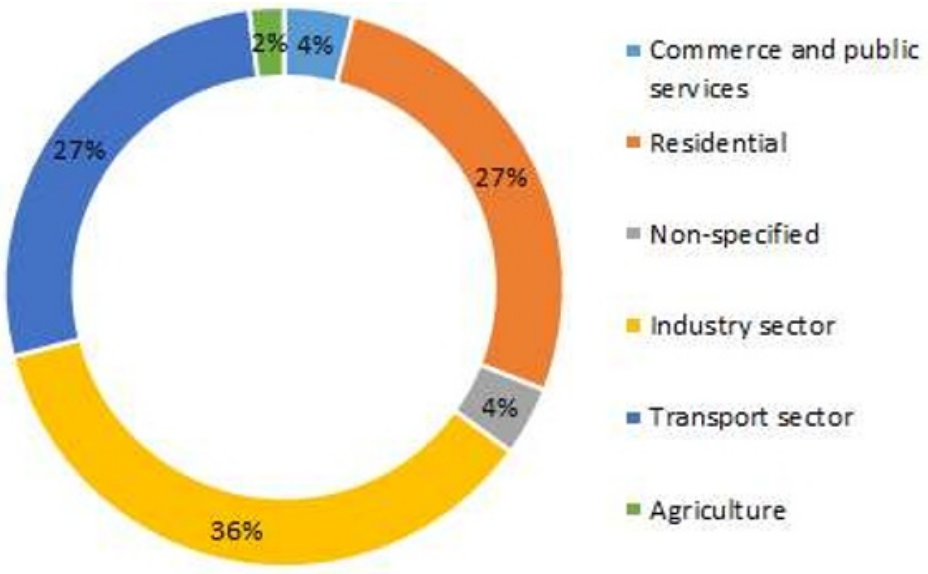

Fig.4. Energy consumption by sector in South African [22]

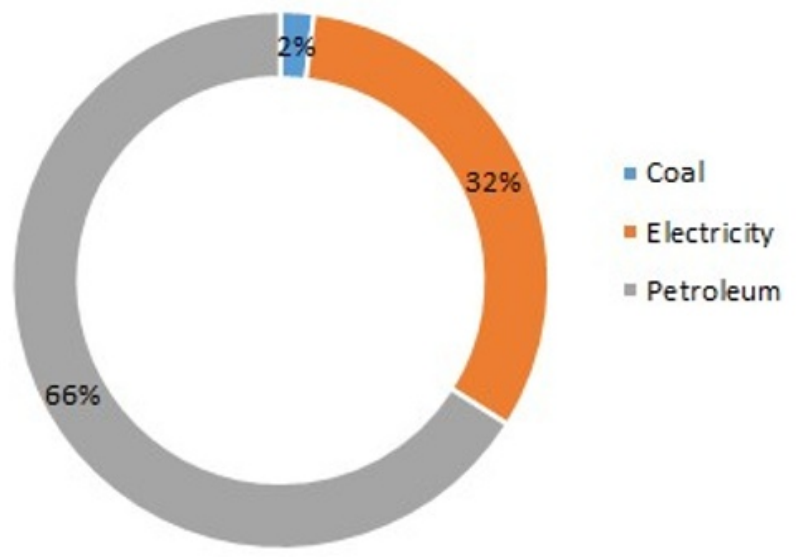

Fig.5.Types and proportions of fuel consumed by South African agricultural sector [22]

Although the Agricultural sector depends mainly on petroleum products, it also is significantly dependent on the electricity grid and is thus one of the affected sectors. Irrigated farms that use pumps for irrigation water have been especially hard hit with rising energy costs. It should also be highlighted that not only is the agricultural sector affected by the reliability and increasing costs of electricity in the country, but the food security itself is at risk with the entire food supply chain being affected. 


\subsubsection{Policy and Regulation}

- Food

South African agricultural exports reached a record high in 2018 at \$10.6-billion, and fell by 8\% in 2019 largely due to the aforementioned drought [24]. These negative impacts on the agricultural sector are also compounded by the energy crisis and rising electricity and fuel costs. Furthermore, there has been recently declining investment in the sector due to policy uncertainty with respect to land reform and agriculture, and poor progression in the informal food production sector due to hegemony of the industrial players together with policy that largely favors them [25]. As suggested in [25], the food-policy challenges of food security, poverty, hunger and inequality in South Africa require coordinated responses across the government as water, energy and economic factors deeply influence the sector.

\section{- Water}

The water scarcity in South Africa, coupled with the estimated population growth and subsequent demand means that a shortfall in supply is expected. Thus, there have been significant infrastructural investments in the country in recent years with plans to improve its capacity. Water management in South Africa is a national competency as declared under the National Water Act, Act No 36 of 1998. The Department of Water and Sanitation is the ministry that is primarily responsible for water in South Africa. As Agriculture is by far the largest consumer of water in South Africa, there is a huge investment opportunity in water resources and infrastructure in this sector [18].

The forecasted scenarios for water demand have been revised in recent years and show improvements, but the revised projections are sufficient to warrant significant concern [26]. According to forecasts and analysis presented [26], it is found that only through markedly improved system efficiencies can water balance be achieved and vulnerabilities arising from other influences such as international commodity shocks. Although there have been some policy and regulation revisions in recent times with respect to water, there still exists gaps which require attention in order to close investment gaps for the necessary infrastructure improvements and to improve system efficiencies.

\section{- Energy}

Energy policy in a democratic South Africa has historically reflected the country's recognition for transition into more sustainable growth and development. In its White Paper on Energy Policy [27] more than twenty years ago, the government recognized the critical importance for renewable energy developments including wind, solar and hydro-power. However, despite further emphasis on this sustainable energy development including revisions to policy such as the White Paper on Renewable Energy [28] and the more recent Integrated Resource Plan [23], the adoption of these policies in terms of implementation has been slow and inadequate. Multiple regulation and policy failures have resulted in further deepening of the energy crisis resulting in huge economic losses and sustained negative impacts on all sectors including the agricultural and food production sector. The true impact of the energy crisis and policy failures is not well understood as the interrelated issues of the need for widening access, improving reliability, extending sustainable generation versus the infrastructure costs, impacts on the environment and sectors of the economy have not been adequately dealt with in studies that inform the policy and regulation.

\subsubsection{WEF nexusframeworks}

Energy and water play an immense role in the context of any country. As has been described, South Africa suffers from the water and energy crises having both short term and long-term effects on the country's agricultural sector and its food security. It should also be highlighted that the policies - and the scenario modeling that informs those policies - are generally done in isolation. This means that compounding or cascading effects of these strongly related issues are not sufficiently accounted for and in some cases not even considered. The risks are thus not adequately evaluated, which means that most plans are revisited because the actions do not prove to have the expected impacts. Although there is awareness of climate change and the nexus on food security, much more work is needed into transitioning this into knowledge that informs policy and regulation, which can lead to improved sustainable development strategies for the country [4]. 


\subsection{Morocco:}

\subsubsection{Agriculture in Morocco: Overview}

Agriculture is one of the pillars of the Moroccan economy. The agricultural production contributes by $15-20 \%$ of the country's GDP and agro-food industry insures $5 \%$ of the national GDP while it covers $30 \%$ ofexport earnings. The sector is very important for job creation and employs about $40 \%$ of the country's workforce depending on the productivity of the year. The cultivated area in Morocco is around 87 million hectares of which 16 million hectares are irrigated. More than $90 \%$ of the country's agricultural production depends on rain and the outputs vary from a year to another. Agriculture products are diverse and permit the supply of the local market and also export. Thus, the main agricultural products are wheat, sugar beet, citrus fruits, tomatoes, potatoes, olives, and olive oil in addition to eggs, meat and milk. However, products such as grains (wheat, barley, maize), sugar, tea and coffee constitute the main food product depending on importation. Grain consumption is characteristic of the food system in Morocco and the national production depends on rainfall and the country imports on average more than $40 \%$ of its needs. On the other hand, Morocco is known to be an exporter of fish and fruits and vegetables mainly to Europe[29]. The main challenge for the Moroccan agriculture is climate variation and the dependency of the sector to rainfall with an over exploitation of water resources for irrigation (use of more than $85 \%$ of mobilized water resources).

\subsubsection{Risks to agricultural food production}

\section{Water quality and availability}

Currently, Morocco reached "water stress" status according to the United Nations Economic Commission for Africa (UNECA) corresponding to $1000 \mathrm{~m}^{3}$ to $1700 \mathrm{~m}^{3}$ of available freshwater per person per year. In the future and by 2025 , the country's water availability will face more difficulties under "water scarcity" state with predictions of less than $1000 \mathrm{~m}^{3}$ of available freshwater per person per year. This situation is resulting in an increase of the water demand from different sectors and from climate instability. Predictions estimate, according to the Food and Agriculture Organization, that Morocco will experience both a decrease of 13 to $30 \%$ in precipitation and an increase of almost 3 degrees Celsius $\left(2.3\right.$ to $\left.2.9^{\circ} \mathrm{C}\right)$ in annual temperatures by 2050 . This impacts directly the recharge of ground water. Agriculture production consequently decreases significantly with a high variation over the years. 7.2 million hectares of agricultural land representing $83 \%$ are not irrigated and yields of major crops rely on rainfall. Significant variations of yields are due to the high variability of rainfall and a high frequency of droughts.

This situation is critical and will be more complicated for ensuring water and food security. In fact, water use efficiency should be increased via integrated water resources management strategies.

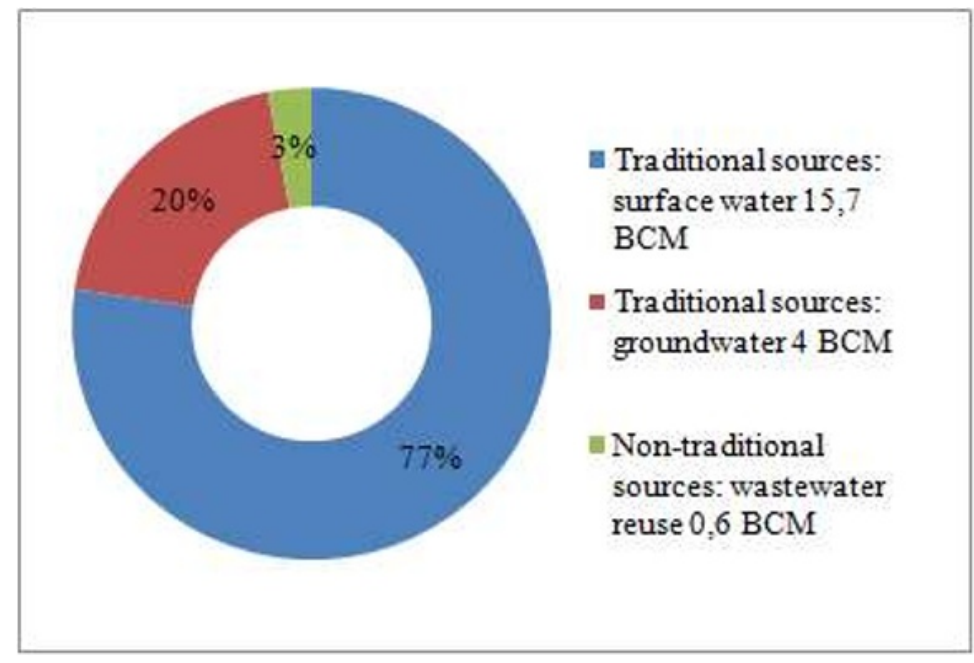

Fig.6. Water Resources in Morocco in billions of cubic meters[30] 


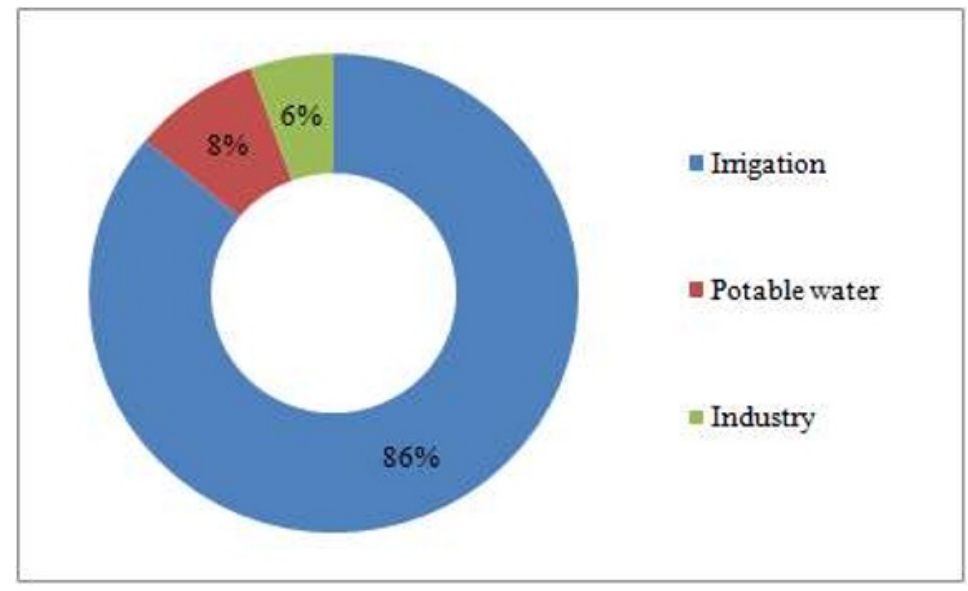

Fig.7. Water utilization in Morocco (\%) [30]

Irrigation consumes more than $85 \%$ of mobilized water (surface and groundwater) in Morocco and this shows the dependency of the agriculture sector on irrigation to insure production and the important pressure of agriculture activities on water resources.

Another big challenge for the water sector in Morocco is the increasing level of urbanization. Thus, urbanization will have a significant influence on water resources availability in the future. $60 \%$ Population of Morocco was residing in urban areas in 2015 and the future projections expect that this percentage will reach $74 \%$ by 2050 . In fact, population growth and rapid urbanization, economic developments will make the competition for water resources across all sectors very complicated. Consequently, this will lead to a depletion of traditional groundwater sources. Meanwhile, water sources will be more and more exposed to contamination through changes in land use changes, weak and difficult solid waste storm water and flooding management, insufficient wastewater treatment, and weak infrastructure especially for places with informal urban expansion. Climate change is adding more uncertainty and vulnerability to these constraints. If water management was not balanced, majority of cities in morocco will be facing a water-insecure future [30].

\section{- Energy availability, reliability and cost}

Morocco's energy sector depends primarily on oil and coal imports that have heavy environmental and financial costs. The production of oil and coal is not present in the country and a small amount of gas is produced and it's oriented to a limited industrial use. The majority of energy needs of the country is coming from oil $(67.6 \%)$ and coal $(16.1 \%)$. This corresponds to $95 \%$ of the total primary energy supply (TPES). Electricity is also imported with an increasing cadence during the last decade in order to satisfy the demand in peak periods [31].

The consumption of energy in Morocco increased during the recent years following the economic growth (an average annual growth of $4 \%$ ), population rise and urbanization expansion [31].

Transport is the most consuming sector of energy in Morocco (35.9\%) followed by the residential sector $(24.9 \%)$, industry sector $(23.6 \%)$, commercial and public services $8.0 \%$ and agriculture and forestry activities $(7.6 \%)$. Consumption in transport and agriculture sectors increased significantly during the last few years while the consumption in residential and industry sectors decreased. However, it remained stable for commercial and public services [31]. Agriculture production activities rely on non-renewable sources of energy (diesel and gas, figure 8) as a mainsource of energy than and electricity as the second source of energy [31].According to the World Bank, the $\mathrm{CO}_{2}$ emissions reached a value of 1.8 million tons per capita which comes mainly from consumption of energy, electricity production and industry. 


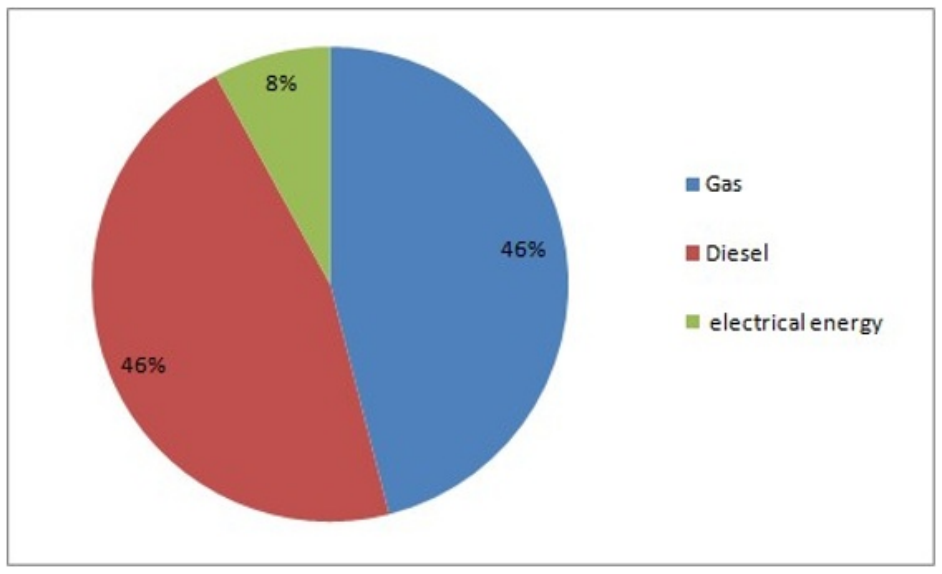

Fig.8. Distribution and types of source of energy consumed by Moroccan agricultural sector [32].

Agriculture sector consumes a significant share of national energy, mainly in irrigation systems (pumping, water distribution), tractors and engines, dryers and livestock buildings (bovine milking blocks, air conditioning and heating systems) in poultry farming, feeding equipment). On the other hand, there is indirect energy consumption resulting from the use of inputs (fertilizers, livestock feeds) and the energy impact of investments in buildings and equipment. In addition to its impact on the environmental quality of rural areas, energy consumption has a significant impact on the economic competitiveness of the Moroccan agricultural sector, severely increasing the operating expenses for producers [32]. Those activities rely mainly on the use of diesel (46\%) and liquid gas (46\%) in addition to a small percentage of electrical energy (8\%) [32].

Separately, food processing (with tobacco plant processing) consumes $11 \%$ of the total consumption of the industrial sector.

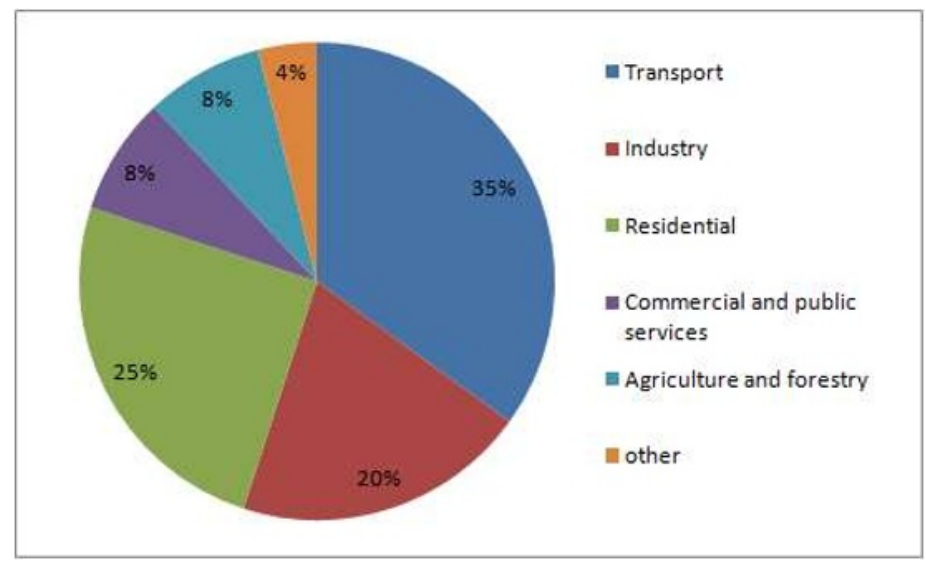

Fig.9. Energy consumption by sector in Morocco (share in TFC)[31]

Taking into consideration the dependency of the Moroccan energy sector of oil and coal imports (Figure 10) and the increasing consumption, the Moroccan government is trying to change this situation by developing renewable energy technologies in order to diversify and to enrich the future energy mix of the country. In fact, Morocco set up a strategic plan to produce more $42 \%$ of its energy needs from renewable energy by 2020 and more than $50 \%$ (20\% solar, 20\% wind, $12 \%$ hydro) by 2030. Currently, the percentage of renewables is around $34 \%$ among the mixture of electricity [32]. 


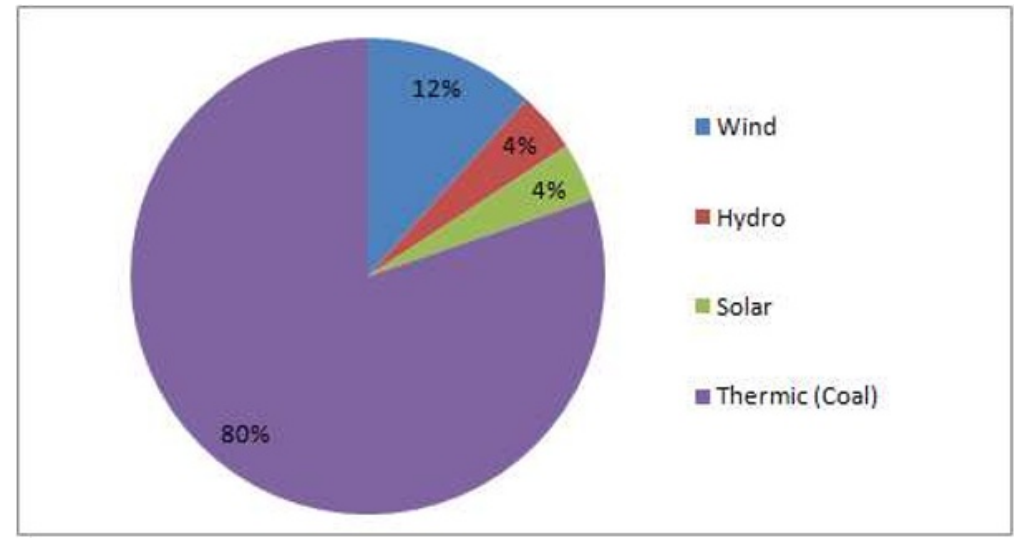

Fig.10. Energy generation mix in Morocco [31]

\subsubsection{Policy and Regulation}

\section{- Food:}

Morocco is known as an exporter of fresh fruits and vegetables especially tomato and oranges. The main external market is the European Union because of the historical and geographical factors. According to that, the food policy of Morocco depends on the EU with whom a pricing system is applied between the 2 partners based on bilateral agreements. Those agreements include the one related to fisheries and fish exportation to the EU countries.

Food production, distribution and control is under the responsibility of the Ministry of Agriculture, Fisheries and forestry. The agricultural production, distribution and packaging professionals are organized in associations and federations specific for the main agricultural productions. On the other hand, agriculture producers are represented by the Agriculture Chamber which is an elected body that ensures the defense of their interests and to contribute in the development of their activities and their organizations. The import and the production of seeds, plants and animals, the use of pesticides, the control of quality of food in the market is the responsibility of the national office of food safety: Office Nationale de Sécurité et Salubrité Alimentaire(ONSSA).The development of agriculture production and valuation of products projects are managed by the Agency for agriculture development. The organization of the food sector and agriculture production changed significantly after the adoption of the Moroccan Green Plan in 2008. This plan aims to double the contribution of agriculture production in the national GDP by 2020.

The Green Morocco Plan (Plan MarocVert, 2008-2020) is a national strategy adopted and implemented to make food systems more sustainable. This strategic plan aimed at the improvement of food security and the promotion of resilience, sustainability and competitiveness of the agriculture sector [33].

The Green Morocco Plan impact was a significant increase of production of certain crops, mainly fruits and vegetables, milk and meats but the problem of commercializing the excess of production occurred. In fact, the future strategy of the food production in Morocco will focus on developing and boosting the food processing sector. A new governmental strategy for agriculture development is under development and named 'Generation Green' that aims to foster the agriculture sector productivity and business for a more added value and job creation.

\section{Water}

Morocco's water policy changed in time in order to face the climate constraints and the increasing and important pressure on water resources. Three important phases characterized the past of Moroccan strategies in the water sector. The first one corresponds to the post-independence era in the sixties where the focus was done on water offer management. During this phase, the hydraulic infrastructure was developed by adopting dams' construction policy in order to ensure water security and currently more than 150 dams of different sizes are available in Morocco with storage capacity of $18 \mathrm{Billion}^{3}$. On the other hand, the development of large irrigated perimeters occurred for the enhancement of the agriculture sector. In a parallel with that, water sanitation development was occurring in urban areas.

During the second period, the Moroccan water policy changed significantly and was marked by the adoption in 1995 after adopting the law 10-95. These law articles aim to optimize and to organize water use in the different sectors and to 
provide equal access to water for the different territories of the country and it insure water security as limited and public resources. The regulations of water production and distribution, the improvement of water development and use in agriculture and the prevention of water pollution and illegal water use are other principles of water law.

The third period started at the beginning of this century with the evolution of water demand and marked by the adoption and the start of implementation of the National Water Plan in 2009. This plan focuses on the role of complementary water management actions for addressing water problems and for the achievement of a coordinated management of supply and demand, while trying to ensure equity in water distribution in rural and urban territories. In fact, this plan encouraged water valuation and water economy. Thus, the National Programme for Water Economy in irrigation (Programme National de l'Économie de l'Eau en Irrigation PNEEI) was adopted for conversion of irrigation systems to drip and pressurized ones.

Non-conventional water resources started to be mobilized during this third period with the adoption of water desalination of seawater and demineralization of brackish water. This phase also was axed on maintaining the quality of water and the protection of the resources against pollution with adoption of the National Plan of Sanitation (Plan National de l'Assainissement Liquide PNA) and the National Programme of household solid waste (Programme National des Déchets Solides Ménagers PNDM).

The water sector in Morocco is characterized by the intervention of many stakeholders. The ministry of infrastructure, transport, logistics and water is the main department for the water sector. Previously, a secretariat of state was dedicated to water and was removed from the last structure of the Moroccan government. The Supreme Council for Water and Climate and the Interministerial Commission for Water are the highest consultative and coordination instances in all water related issues. Planning and decision making for water sector includes the participation of the department of Agriculture, Fisheries and Forestry department, the internal affairs department, the health department and the economy and finance department in addition to the department of water.

Water management includes the intervention of the River basin agencies (RBAs), considered as the most important institutional instance in water resources management; The regional offices for agriculture enhancement are the mean institution for management, distribution and use in agriculture that are controlling large scale irrigated perimeters in the country. Water use and management for drinkable water services and sanitation sector is mainly controlled by the National Office for Electricity and Potable Water, Private companies and Local municipalities. The sector is characterized by the presence of water users association, especially in the agriculture sector but also for drinkable water, especially in rural areas.

\section{- Energy}

The energy sector belongs to the Ministry of Energy, Mines and Environment with also the presence of an important institution involved in the energy sector. The mean public institution in energy sector are : (1) The National Agency for Electricity and Water (Office National de l'Électricité et de l'Eau potable, ONEE) is a government-owned vertically integrated utility, (2) The Moroccan Agency for Sustainable Energy (MASEN) which is a limited company than includes many public shareholders responsible for the deployment of renewable energy, (3) the Institute for Research into Solar and Renewable Energies (Institut de Recherche en Énergie Solaire et Énergies Nouvelles, IRESEN) is an agency for energy research, development and innovation (RD\&I) created in 2011 in order to support the national energy strategy through applied research and innovation and (4) The Moroccan Agency for Energy Efficiency (AMEE Agence Marocaine pour l'Efficacité Énergétique) [34].

The presence of such an institutional organization helped in fostering the change in the national strategies for energy management and development.

In the last decade Morocco has been adopting new legislative text, policies and strategies in the energy sector in order to respond to the future challenges of the energy sectors and related issues. The government adopted the National Priority Action Plan for Energy from 2008-2012 and in 2009 the National Energy Strategy was launched. In 2013 a national debate was launched by the Moroccan Agency for Energy Efficiency for adopting a new national Energy Efficiency Strategy for 2030 in order to significantly reduce the energy consumption in different sectors. The draft of this strategy was presented by the government but its adoption is not official yet. An action plan was prepared in parallel with this strategy in order to implement a series of actions in the different regions of the country with the participation of the different ministries (transport, housing, interior, industry, agriculture and finance) with responsible ministry and agencies. A positive economic, environmental and societal impact is expected as a result of this action plan in the energy sector [30].

On the other hand, a Law 47-09 on energy efficiency was adopted in September 2011 for creating a legal framework for improving energy efficiency across the different economic sectors. 
Initiatives in the agriculture sector for reducing its energy consumption bill and its carbon footprint are conducted by the Ministry of Agriculture, forestry and rural development and the Moroccan Agency for energy efficiency (AMEE). The AMEE intervenes at the level of control energy consumption: develop alternative energy, through a program dedicated to promoting solar pumping, and on second level for reducing energy consumption, through a program aiming the optimization of energy performance of farms, launched in partnership with Crédit Agricole du Maroc which is a public bank [32].10 pilot farms were identified for testing the control and reduction of energy consumption and the results were promising and a guide of the best practices of energy efficiency and the use of renewables in Moroccan agriculture production sites. On the other hand, subsidies of solar pumping equipment are scheduled by the Ministry of agriculture in the short term for the replacement of diesel and liquid gas for water pumping.

\subsubsection{WEF nexusframeworks}

Water scarcityin Morocco is becoming very serious in recent years. In fact, alternative solutions to freshwater under stress needs to be found and adopted urgently. Desalination of seawater is one of the promising solutions. Moroccan has a very long coastal line, nearly 2,000 km (Atlantic Ocean and the Mediterranean Sea), offering an ample sea and ocean water to desalinate. However, important investments are required for water treatment into the high cost of energy required for running the treatment plant. The desalination plants can satisfy or replace the pressure on groundwater and surface water used mainly for irrigation of crops (More than $85 \%$ of mobilized freshwater resources). This will contribute significantly in the reduction of variation of rainfall over the years and the potential climate change on crop production and food security in the country. Thus, Morocco has to find a solution to its dependency on oil and coal imports for energy production and invest in integrated renewable energy production and water desalination plants. The water energy nexus needs to be studied in order to evaluate the impacts of such a kind of solution and different future scenarios and the most sustainable solution for water. One of the initiatives on the nexus concerns a Water-Energy Nexus platform which was planned to be launched in 2019 by IRESEN and will be dedicated to water treatment, water desalination, and the linkages between the energy and water sectors [30]. This platform is an example of solutions that may help in disseminating technical reports and exposing successful experiences and best practices related to the water energy nexus and that will impact automatically the agriculture sector and food security of the country.

\subsection{General overview on food security in both countries:}

Cereal import dependency ratio and the value of food imports in total merchandise exports [35] are two important FAO indicators that can help analyzing food security in a specific country. They are used to evaluate partially the stability criteria as one the food security pillars in both countries Morocco and South Africa. The third indicator that was compared is the average value of food production which is on the criteria used to evaluate availability as also a pillar of food security.

\subsubsection{Cereal import dependency ratio}

The most important cereals are Maize, rice and wheat. They constitute the most widely cultivated crops in the world and the foundation of world food security. On the other hand, they are critical to food security especially in the developing regions. In the Southern Africa region, they make up half the calorie supply [36]. Thus, this ration was chosen to compare the situation of food security in Morocco and South Africa based on this ratio.

The analysis of the available data for those indexes (Fig.11) shows that Morocco has a higher ratio for cereals import dependency compared to the ratio of South Africa and compared to the world ratio that is about 16 percent [35] and the one of the developing countries that is 15.5 percent [35]. However, the South African ratio is still low compared to these two values. Negative values reveal Morocco's dependency on cereals imports because the cereals production in the country is mainly practiced in rain-fed areas and still relies on rainfall which is directly related to water resources and water statusof the country. Variation in the Moroccan is due the introduction of new varieties more tolerant to drought and a change in the cultivation system (zero-tillage cultivation, fertilization) in addition to climate variation that is the main factor of this variation. 


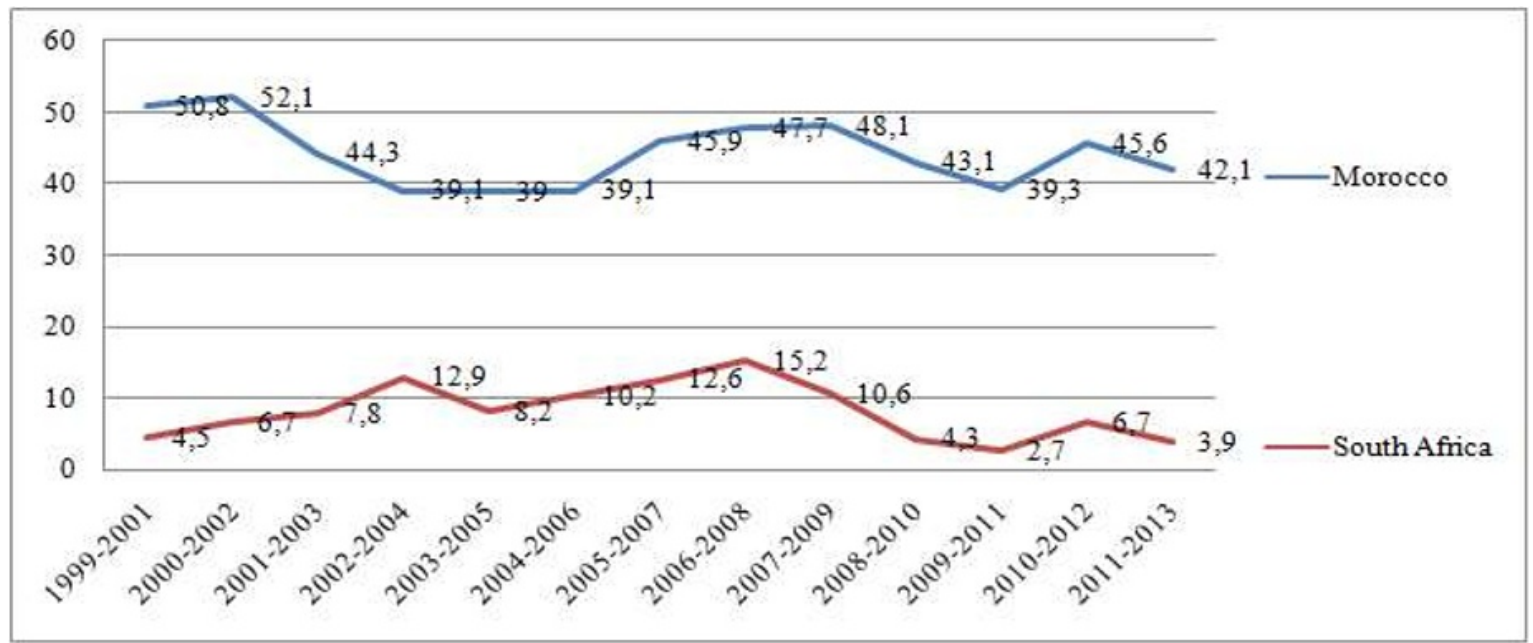

Fig.11. Evolution of Cereal import dependency ratio (\%) for 3 years periods in Morocco and South Africa (Compiled from [35])

\subsubsection{Value of food imports in total merchandise exports}

The value of food imports in total merchandise exports indicator provides a measure of vulnerability and captures the adequacy of foreign exchange reserves to pay for food imports, which has implications for national food security depending on production and trade patterns. The analysis of the available data for this indicator shows a higher value for Morocco indicator in comparison with its value for South Africa (Fig.12) and to the average value for the World that is around $5 \%$ [35]. This shows that this indicator South Africa is not higher and the export value of goods permits to cover the food imports. This shows how important the foreign trade balance and its direct connection and influence on food security that is represented here by the value of food export.

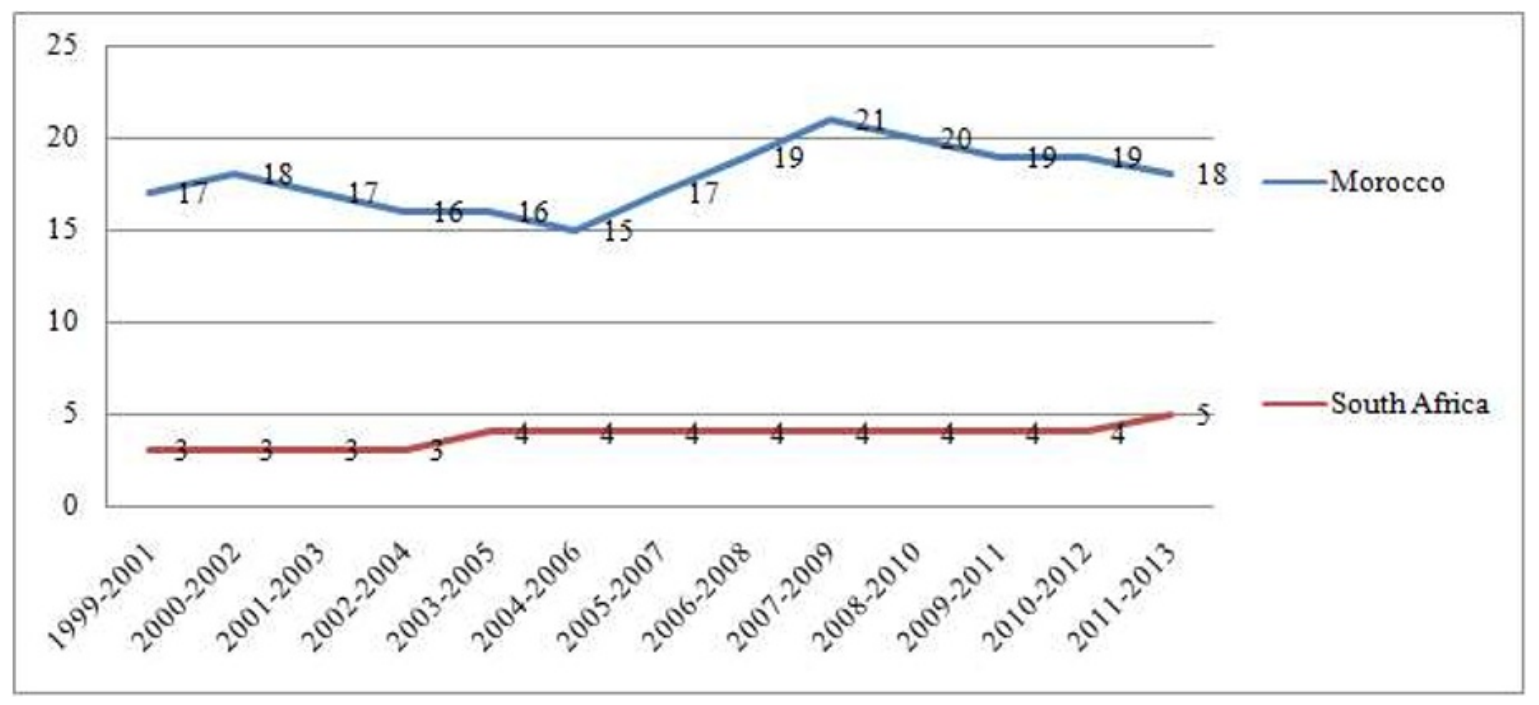

Fig.12. Evolution of Value of food imports in total merchandise exports (\%) for 3 years periods in Morocco and South Africa (Compiled from [35])

\subsubsection{Average value of food production}

The average value of food production provides a cross country comparable measure of the relative economic size of the food production sector in both countries. The comparison of this value for Morocco and South Africa showed an aligned evolution across the years with slightly higher values for Morocco between 2008 and 2016 period (Fig. 13). However, the values for both countries are lower the average value for food production in the world which is around 283 (constant 2004 - 
2006 I\$ /cap), and very low in comparison of the average of the higher income countries that have a value around 480 (constant 2004-2006 I\$/cap) for the same periods of years [35].

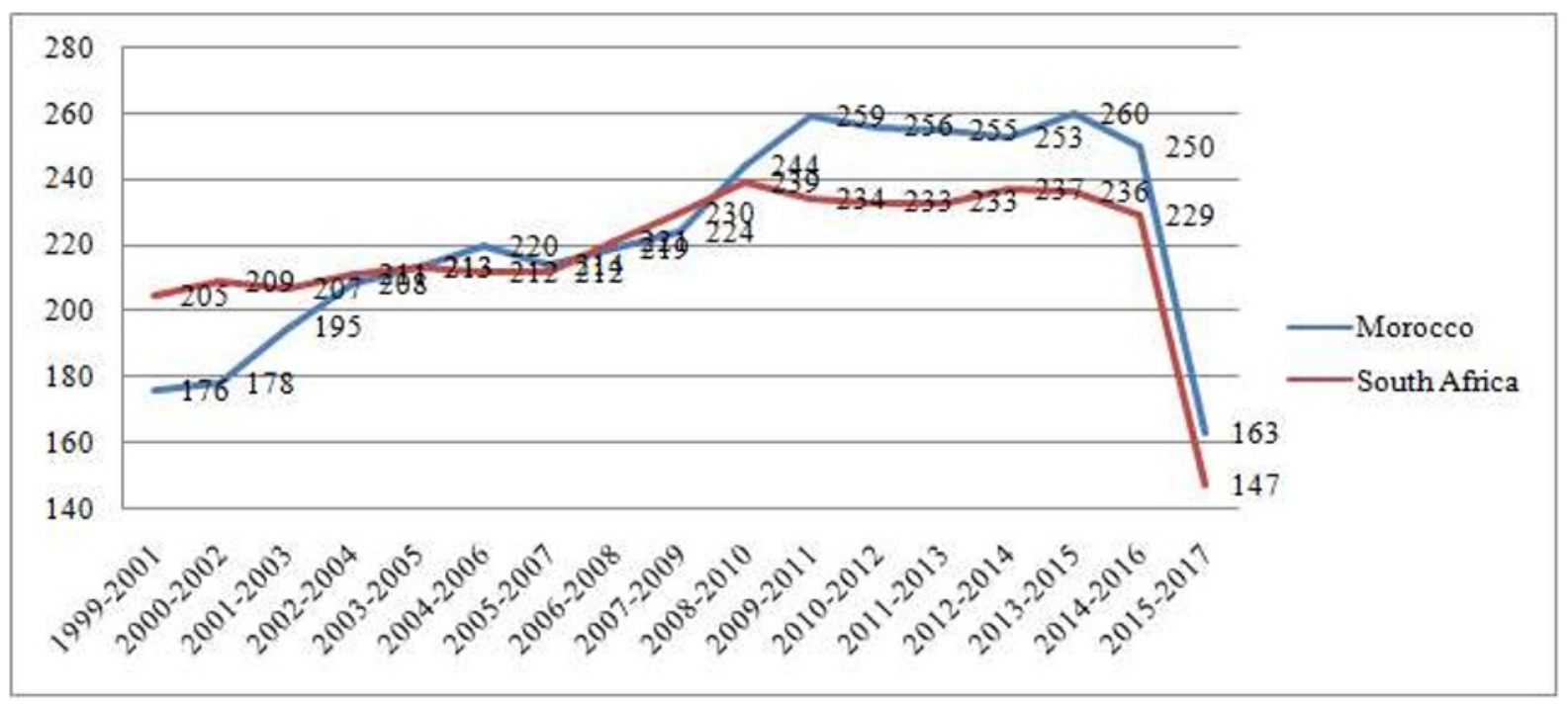

Fig.13. Evolution of the average value of food production (constant 2004-2006 I\$/cap) (3-year average) for Morocco and South Africa (Compiled from [35])

\section{Conclusion}

This review paper aims to compare the statute of the Water Energy and Food nexus in Morocco and South Africa and describe the basic frameworks in both countries. It is found that the existing frameworks are inadequate and do not sufficiently reflect, or not all in most instances, the interconnection between the different components of the Nexus especially for the agricultural sector and with respect to food security. Although the water and energy systems are well developed in both countries, there is a need to develop more complex and complete WEF Nexus frameworks for both countries.

The research of WEF Nexus policies showed that there is a lack of policies that take into consideration all the nexus components. In fact, one of the key findings in this paper is that policies are largely formed in "isolation", and there is a lack of consideration of interdependencies - i.e. WEF Nexus in both countries. For this reason, it is thus impracticable to even begin to make meaningful comparisons and direct analyses of risks for water, energy and food components. There is overwhelming evidence to indicate as the complexity of these systems grows, assessments and analyses in practice are best made via the WEF Nexus. The complexity of gathering data and modeling these complex interconnections is also recognized and thus technology-assisted WEF nexus frameworks are suggested in this paper as a means toward overcoming challenges with implementation. Finally, it is recommended that models for the evaluation of the WEF Nexus be adopted as test approaches of the policy makers in Morocco and South Africa, which is expected to significantly contribute in informing and facilitating the decision making process.

\section{References}

1. H. Bellfield. Water, Energy and Food Security Nexus in Latin America and the Caribbean, (IUCN/IWA/GIZ, 2015)

2. D. Conway, E. A. Van Garderen, D. Deryng, S. Dorling, T.Krueger, W. Landman, B. Lankford, Nat Clim Chang 9 (2015)

3. G. Simpson, T. Mabhaudhi, J. Badenhorst, M. Mohammed, T. Motongera, A. Senzanje, G. Jewitt Assessing the State of the Water-Energy-Food (WEF) Nexus in South Africa (2018) 
4. S. Carter, M. Gulati, Climate change, the Food Energy Water Nexus and food security in South Africa. Understanding the Food Energy Water Nexus. WWF-SA, South Africa, (2014)

5. R. Ferroukhi, D. Nagpal, A. Lopez-Peña, T. Hodges, R. Mohtar, B. Daher, M. Keulertz, Renewable energy in the water, energy, and food nexus, (IRENA, 2015)

6. M. Sajid, I. Muhammad, R. Muhammad, B. Saqib, Y. Gutha.A Report on Water, Energy and Food Relationship.Int.J. of Nutr.,3 (2019)

7. J.J. Urban, Joule, 1 (2017)

8. B. Daher, R. H. Mohtar, H. Lee, A. Assi, “Modeling the water-energy food nexus, ” in Water-Energy-Food Nexus: Principles and Practices, eds P. Abdul Salam, S. Shrestha, V. Prasad Pandey, and A. K. Anal (Washington, DC: John Wiley and Sons, Inc., 2017)

9. C. Zhang,X.ChenY., Li,W. Ding, G. Fu, J.ofclean.prod., 195 (2018)

10. R. Govindan, T. Al-Ansari, Renew. Sust. Energ. Rev., 112 (2019)

11. Y. Nie, S.Avraamidou, X. Xiao, E.N.Pistikopoulos, J. Li, Y.Zeng, F. Song, J. Yu, M.Zhu, Total Environ., 659 (2019)

12. E. Eftelioglu, E. Jiang, X. Tang, S. Shekhar2017. The nexus of food, energy, and water resources: Visions and challenges in spatial computing, in Advances in geocomputation, Springer, Cham (2017)

13. K.T. Sanders, S.F. Masri, J.clean. prod., 117 (2016)

14. Department of Agriculture, Forestry and Fisheries (DAFF),(Strategic Plan. Republic of South Africa, 2015)

15. Bureau of Food and Agricultural Policy (BFAP), (BFAP Baseline: Agricultural Outlook (2018-2027), 2014).

16. Parliamentary Monitoring Group (PMG) .Drought update: Provinces' state of readiness for $2019 / 20$ planting season, National Assembly Committee on Agriculture, Land Reform and Rural Development, Meeting Summary, (2019) https://pmg.org.za/committee-meeting/29261/

17. IBP Inc.,South Africa Investment and Business Guide. Volume 1 Strategic and Practical Information. Lulu.com:World Business and Investment Library, (2015).

18. Reddick J., R. Kruger, Water market intelligence report. (Green Cape, 2019).

19. I. Kuschke, A. Cassim, Sustainable Agriculture: Market Intelligence Report 2019, GreenCape (2019)

20. Department of Agriculture, Forestry and Fisheries (DAFF, (Economic Review of the South African Agriculture 2017/18. Republicof South Africa, 2018).

21. K. Ratshomo, R.Nembahe, South African energy sector report. Department of Energy - Republicof South Africa, 2018)

22. Department of Energy (DoE), The South African Energy Sector Report 2019, (Republic of South Africa, 2019)

23. Department of Energy (DoE), Integrated Resource Plan, (Republicof South Africa, 2019)

24. W. Sihlobo,(Understanding South Africa's agriculture trade patterns, Daily Maverick, 2020) https://www.dailymaverick.co.za/opinionista/2020-02-17-understanding-south-africas-agriculture-tradepatterns/\#gsc.tab $=0$

25. T. von Bormann (WWF-South Africa, 2019)

26. Z. Donnenfeld, C. Crookes, S.Hedden. A delicate balance: Water scarcity in South Africa, (ISS Southern Africa Report, 2018)

27. DME, White paper on the energy policy of the Republic of South Africa (Department of Minerals and Energ, 1998). http://www.energy.gov.za/files/policies/whitepaper_energypolicy_1998.pdf

28. Department of Minerals and Energy (DME) (White paper on renewable energy, Republic of South Africa, 2003)

29. Agence pour le DéveloppmentAgricole (ADA), (investor's guide in the agricultural sector in Morocco, 2015)http://www.agriculture.gov.ma/sites/default/files/investors_guide_in_the agricultural_sector_in_morocco.pd f 
30. World Bank Group (WBG) (Managing Urban Water Scarcity in Morocco, 2017) https://openknowledge.worldbank.org/handle/10986/29190

31. International Energy Institution (IEA)(Energy policies beyond IEA countries: Morocco, 2019)

32. AMEE Agence Marocaine pour l'Efficacité Énergétique, Website, http://www.amee.ma/index.php?option=com content\&view=article\&id=138\&Itemid=232\&lang=fr

33. World Food Programme WFP, Morocco country strategic plan (2019-2021), Executive Board document, Annual session Rome, 10-14 June 2019)

34. MMEME, Moroccan Ministry of Energy, Mines and Environment Website, (2019) http://www.mem.gov.ma/SitePages/Ministere/Organigramme.aspx\#

35. FAO. FAOSTAT, (AccessedMay 15, 2020) http://www.fao.org/faostat/en/\#data/FS.

36. FAO, (Save and Grow: Maize, Rice and Wheat: A Guide to Sustainable Crop Production, 2016). http://www.fao.org/3/a-i4009e.pdf 